\title{
Use of the Charge Transfer Reactions for the Spectrophotometric Determination of Risperidone in Pure and in Dosage Forms
}

\author{
Hemavathi Nagaraju Deepakumari and Hosakere Doddarevanna Revanasiddappa \\ Department of Chemistry, University of Mysore, Manasagangothri, Mysore 570006, India \\ Correspondence should be addressed to Hosakere Doddarevanna Revanasiddappa; hdrevanasiddappa@yahoo.com
}

Received 30 September 2012; Accepted 31 October 2012

Academic Editor: Giovanni Lentini

Copyright (C) 2013 H. N. Deepakumari and H. D. Revanasiddappa. This is an open access article distributed under the Creative Commons Attribution License, which permits unrestricted use, distribution, and reproduction in any medium, provided the original work is properly cited.

\begin{abstract}
The aim of study was to develop and validate two simple, sensitive, and extraction-free spectrophotometric methods for the estimation of risperidone in both pure and pharmaceutical preparations. They are based on the charge transfer complexation reactions between risperidone (RSP) as $n$-electron donor and $p$-chloranilic acid ( $p$-CA) in method A and 2,3-dichloro-5,6-dicyano1,4-benzoquinone (DDQ) in method B as $\pi$-acceptors. In method A, RSP reacts with $p$-CA in methanol to produce a bright pinkcolored chromogen measured at $530 \mathrm{~nm}$ whereas, in method B, RSP reacts with DDQ in dichloromethane to form orange-colored complex with a maximum absorption at $460 \mathrm{~nm}$. Beer's law was obeyed in the concentration range of $0-25 \mathrm{and} 0-50 \mu \mathrm{g} / \mathrm{mL}$ with molar absorptivity of $1.29 \times 10^{4}$ and $0.48 \times 10^{4} \mathrm{~L} / \mathrm{moL} / \mathrm{cm}$ for RSP in methods A and B, respectively. The effects of variables such as reagents, time, and stability of the charge transfer complexes were investigated to optimize the procedures. The proposed methods have been successfully applied to the determination of RSP in pharmaceutical formulations. Results indicate that the methods are accurate, precise, and reproducible (relative standard deviation $<2 \%$ ).
\end{abstract}

\section{Introduction}

Risperidone (RSP) chemically known as 4-[2-[4-(6fluorobenzo[ $d]$ isoxazole-3-yl)-1-piperidyl]ethyl]-3-methyl2,6-diazabicyclo[4.4.0]deca-1,3-dien-5-one (Figure 1), is the atypical antipsychotic drug with a relatively low incidence of extra pyramidal side effects. It is used for the treatment of schizophrenia, bipolar disorder, and behavior problems in people with autism. In 2003, the FDA-approved RSP for the short-term treatment of the mixed and manic states associated with bipolar disorder. It is also approved for the treatment of irritability in children and adolescents with autism in 2006. The drug is officially included in 2005 European Pharmacopeia, and the official method of its determination is high-performance liquid chromatography [1].

Many methods have been employed for the determination of RSP in biological samples including HPLC with electrochemical detection $[2,3]$ and RP-HPLC with UV detection [4]. The most extensively used technique for its determination is LC-MS/MS, but several procedures using this technique are confined to biological fluids like human plasma [5-8], plasma and urine [9], and serum [10]. A limited number of analytical methods for the quantitative estimation of RSP in pharmaceutical samples are known. Procedures based on high-performance liquid chromatography and thinlayer densitometric methods [11], spectrophotometry [12, 13], and gas chromatography [14] are available in the literature. The reported chromatographic techniques $[11,14]$ require expensive experimental setup, whereas the cited spectrophotometric methods: one is uv method [12] and another [13] requires extraction step for RSP determination. Thus, there is a need to develop sensitive, accurate, and economical methods for its determination.

In the present study, the authors have described the development and validation of two simple and sensitive spectrophotometric methods for the analysis of RSP in pure form and in pharmaceutical samples using $p$-CA and DDQ as $\pi$-acceptors. The developed methods were validated for linearity, accuracy, and precision. 


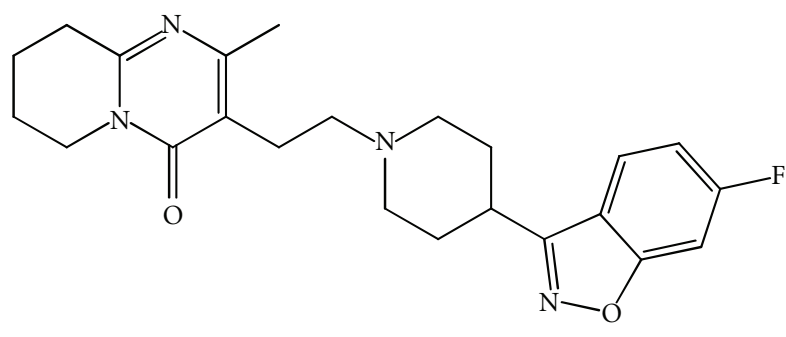

FIGURE 1: Structure of risperidone.

\section{Experimental Section}

2.1. Apparatus. All absorbance measurements were performed using a Systronics Model 166 digital spectrophotometer provided with $1-\mathrm{cm}$ matched quartz cells.

2.2. Reagents and Standards. All chemicals and reagents used were of analytical reagent grade, and distilled water was used throughout the investigation.

(i) p-Chloranilic acid $(0.05 \%, \mathrm{w} / \mathrm{v})$ : it was freshly prepared by dissolving $0.05 \mathrm{~g} p$-chloranilic acid (Rolex, Mumbai, India) in $100 \mathrm{~mL}$ acetone.

(ii) 2,3-Dichloro-5,6-dicyano-1,4-benzoquinone $\quad(0.1 \%$, $\mathrm{w} / \mathrm{v})$ : it was prepared by dissolving $0.1 \mathrm{~g} 2,3$-dichloro5,6-dicyano-1,4-benzoquinone (Avra synthesis Pvt. Ltd., Hyderabad, India) in $100 \mathrm{~mL}$ acetonitrile.

(iii) Standard RSP solution: pharmaceutical grade RSP, certified to be $99.98 \%$ pure, was received from Cipla India Ltd., Mumbai, India, as a gift sample and was used as such. A stock standard solution equivalent to $100 \mu \mathrm{g} / \mathrm{mL}$ of RSP was prepared separately by dissolving $10 \mathrm{mg}$ of the pure drug in $100 \mathrm{~mL}$ methanol in method $\mathrm{A}$ and in $100 \mathrm{~mL}$ dichloromethane in method B. Working solutions were prepared as required by dilution with respective solvents.

Pharmaceutical formulations of RSP such as Respidon (Torrent (Mind)) and Rispond (Micro Synapse) were purchased from local markets.

\subsection{General Procedures for Calibration Graph}

2.3.1. Method A. An aliquot of standard solution containing $0.0,0.25,0.5,1.0,1.5, \ldots, 5.0 \mathrm{~mL}(50 \mu \mathrm{g} / \mathrm{mL})$ of RSP was transferred into a series of $10 \mathrm{~mL}$-calibrated flasks. To this solution was added $3.5 \mathrm{~mL} 0.05 \%$ p-CA, then shaken well, and the contents were diluted to the mark with methanol and mixed well. The absorbance of the bright pink-colored complex was measured at $530 \mathrm{~nm}$ after $5 \mathrm{~min}$ against the reagent blank prepared similarly, but without drug content.

2.3.2. Method $B$. Aliquots of a standard drug solution ranging $0.0,0.5,1.0,1.5,2.0 \ldots, 5.0 \mathrm{~mL}(100 \mu \mathrm{g} / \mathrm{mL})$ were taken in a series of $10 \mathrm{~mL}$-calibrated flasks. Then, to each flask $1.5 \mathrm{~mL}$ of $0.1 \%$ DDQ was added. The contents were diluted to the mark with dichloromethane and mixed well, and the absorbance of the colored product was measured at $460 \mathrm{~nm}$ against the reagent blank. The amount of RSP present in the sample was computed from calibration curve or the regression equation.

2.4. Procedure for Pharmaceutical Preparations. Thirty tablets each containing $1 \mathrm{mg}$ of RSP were weighed and finely powdered. An accurately weighed amount of the powder equivalent to $10 \mathrm{mg}$ of RSP was transferred separately into $100 \mathrm{~mL}$-calibrated flasks and $10 \mathrm{~mL}$ each of methanol for method A and dichloromethane for method B was added. The content was shaken for about $30 \mathrm{~min}$; the volume was diluted to the mark with respective solvents and mixed well and filtered using a Whatman No. 41 filter paper. The filtrate containing RSP (at a concentration of $100 \mu \mathrm{g} / \mathrm{mL}$ ) was subjected to analysis by the procedures described above.

2.5. Procedure for the Analysis of Placebo Blank and Synthetic Mixture. A placebo blank containing starch $(10 \mathrm{mg})$, acacia (15 mg), hydroxyl cellulose (10 mg), sodium citrate $(5 \mathrm{mg})$, talc $(15 \mathrm{mg})$, magnesium stearate $(20 \mathrm{mg})$, and sodium alginate $(10 \mathrm{mg})$ was prepared by combining all components to form a homogeneous mixture, and its solution was prepared as described under "Procedure for pharmaceutical preparations" and was subjected to analysis by following the general procedures. A synthetic mixture was separately prepared by adding pure RSP $(20 \mathrm{mg}$ ) to placebo blank, and the extract was prepared by diluting to give RSP $(100 \mu \mathrm{g} / \mathrm{mL})$ and was used in both methods A and B, respectively.

Synthetic mixture solution prepared above was taken at three different concentrations equivalent to 5,10 , and $15 \mu \mathrm{g} / \mathrm{mL}$ in method $\mathrm{A}$ and 10,20 , and $30 \mu \mathrm{g} / \mathrm{mL}$ in method $\mathrm{B}$ and was subjected to analysis by following the general procedures. The results of the study indicate that the common tablet excipients did not interfere in the assay.

2.6. Stoichiometry. Job's method of continuous variation [15] was employed to establish the stoichiometry of the colored products. The solutions equivalent to $1.22 \times 10^{-4}$ and $2.44 \times 10^{-4} \mathrm{M}$ RSP were prepared. Further, $1.22 \times 10^{-4} \mathrm{M}$ p-CA and $2.44 \times 10^{-4} \mathrm{M}$ DDQ solutions were prepared in acetone and acetonitrile, respectively. A series of solutions were mixed in complimentary proportions; in method A, the volume was completed up to the mark using methanol, and with dichloromethane in method B. The absorbances of the resulting solutions were measured at their respective wavelengths $\left(\lambda_{\max }\right)$ against the reagent blank under the similar conditions. Job's method of continuous variations graph for the reaction between RSP and $p$-CA or DDQ (Figure 2) shows that the interaction occurs on an equimolar basis via the formation of charge-transfer complexes in the ratio $1: 1$ (RSP : $p$-CA or DDQ).

\section{Results and Discussion}

3.1. Chemistry of the Colored Product. The methods involve charge-transfer (C-T) complex formation between the basic nitrogenous RSP as $n$-donor and $p$-chloranilic acid ( $p$ CA) and DDQ as $\pi$-acceptors in polar solvents. In each 
<smiles>Cc1nc2n(c(=O)c1CCN1CCCCn3c1nc(C)c(CCN1CCC(c4noc5cc(F)ccc45)CC1)c3=O)CCCC2</smiles><smiles>Cc1nc2n(c(=O)c1CCN1CCC(c3noc4cc(F)ccc34)CC1)CCCC2</smiles><smiles>[O-]C1C(O)=C(Cl)C(O)C(O)=C1Cl</smiles>

SCHEme 1: Proposed reaction scheme for method A.

case, the formed charge-transfer complex was subsequently dissociated into radical anions, which are colored species. In method $\mathrm{A}$, an intense bright-pink-colored product was formed by the interaction of donor $n$-electrons of RSP, and $\pi$-acceptor $p$-CA in acetone-methanol solvent system showed absorption maxima at $530 \mathrm{~nm}$ due to the formation of the corresponding $p$-CA radical anion. A DDQ-RSP charge transfer complex exhibits a maximum absorption at $460 \mathrm{~nm}$; this is due to the formation of DDQ radical anion arising from the complete transfer of $n$-electrons from RSP to acceptor DDQ in acetonitrile-dichloromethane solvent, in method B.

In polar solvents such as methanol or dichloromethane, complete electron transfer from the donor to the acceptor moiety takes place with the formation of intensely colored radical anions [16], as per the following equation:

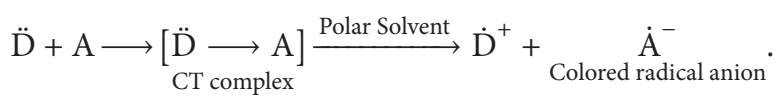

Thus, $p$-CA and DDQ were used as reagents in the proposed methods A and B, respectively, for the estimation of RSP. The possible reaction pathway for RSP- $p$-CA and RSPDDQ complexes was proposed and depicted in Schemes 1 and 2 , respectively.

The reaction stoichiometry between RSP and $p$-CA or DDQ was evaluated by applying Job's method of continuous

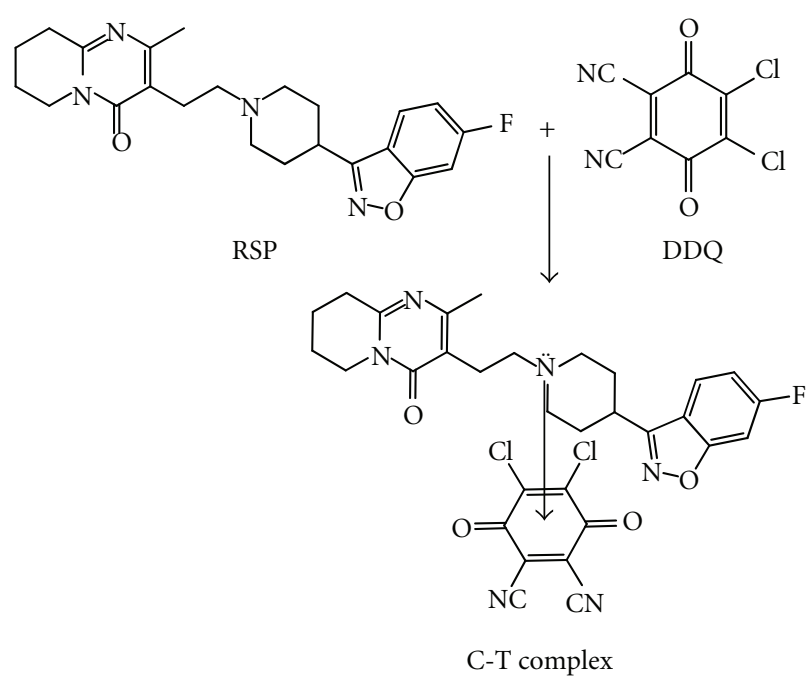<smiles>Cc1nc2n(c(=O)c1CC[NH+]1CCC(c3noc4cc(F)ccc34)CC1)CCCC2</smiles>

Scheme 2: Proposed reaction scheme for method B.

variations. Job's plot (Figure 2) reached a maximum value at a mole fraction of 0.5 which suggested a donor (RSP) to acceptor ( $p$-CA or DDQ) ratio of $1: 1$. This indicated the presence of $n$-donating center in the RSP base for charge transfer complexation reaction.

3.2. Optimization of Experimental Parameters. The factors affecting the formation of charge-transfer complexation, reproducibility, sensitivity, and adherence to Beer's law were investigated and are reported below.

3.2.1. Effect of $p$-CA Concentration. In order to study the effect of the volume of the reagent on the absorbance of the charge transfer complex, varying volumes of $0.05 \% p$-CA were mixed with $10 \mu \mathrm{g} / \mathrm{mL}$ drug in a $10 \mathrm{~mL}$-calibrated flask and diluted to volume with methanol. Highest absorbance was obtained with $3.0 \mathrm{~mL}$, which remained unaffected by further addition of $p$-CA. Hence, $3.5 \mathrm{~mL}$ of the reagent was used for the determination of RSP in method A.

3.2.2. Effect of DDQ Concentration. To establish the optimum experimental condition, risperidone $(10 \mu \mathrm{g} / \mathrm{mL})$ was allowed to react with different volumes $(0-3 \mathrm{~mL})$ of $0.1 \%$ DDQ. Highest absorbance was obtained with $1.0 \mathrm{~mL}$, which remained unaffected by further addition of DDQ. Thus, a volume of $1.5 \mathrm{~mL}$ of DDQ was used for the determination of RSP in method B. 


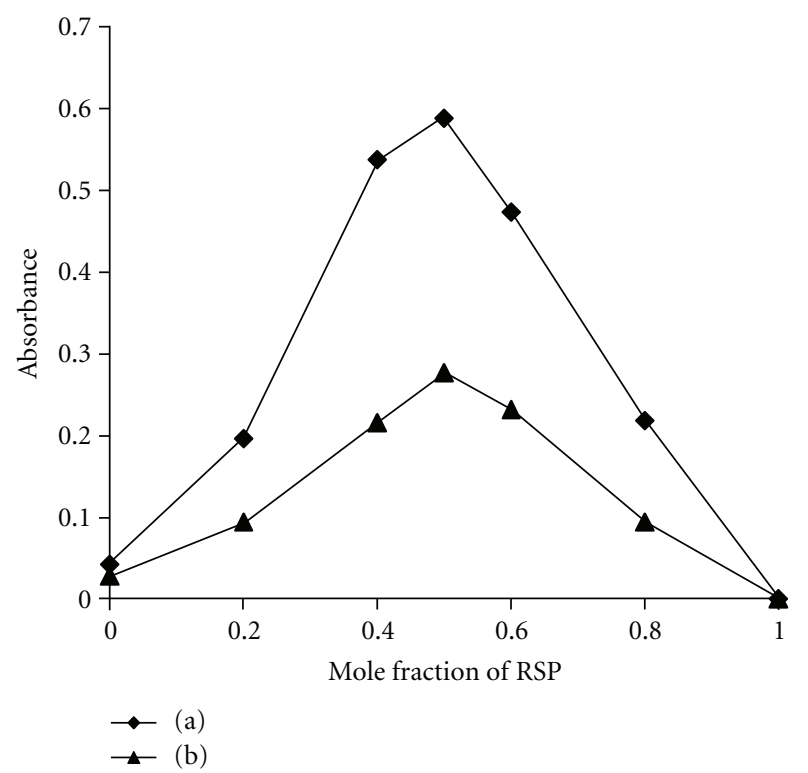

FIGURE 2: Job's plot for stoichiometric ratio for (a) (RSP) and ( $p$-CA) $=\left(1.22 \times 10^{-4} \mathrm{M}\right)$ and $(\mathrm{b})(\mathrm{RSP})$ and $(\mathrm{DDQ})=\left(2.44 \times 10^{-4} \mathrm{M}\right)$.

TABLE 1: Analytical and regression parameters of the proposed methods.

\begin{tabular}{lcc}
\hline Parameter & Method A & Method B \\
\hline$\lambda_{\text {max }} \mathrm{nm}$ & 530 & 460 \\
$\begin{array}{l}\text { Beer's law range } \\
(\mu \mathrm{g} / \mathrm{mL})\end{array}$ & $0-25$ & $0-50$ \\
Molar absorptivity $(\varepsilon)$, & $1.29 \times 10^{4}$ & $0.48 \times 10^{4}$ \\
$(\mathrm{~L} \mathrm{~mol} / \mathrm{cm})$ & & \\
Sandell's sensitivity & 0.0319 & 0.0852 \\
$\left(\mu \mathrm{g} / \mathrm{cm}^{2}\right)$ & & \\
Regression equation & \\
Intercept $(a)$ & 0.0152 & 0.0097 \\
Slope $(b)$ & 0.0296 & 0.0104 \\
Correlation coefficient $(r)$ & 0.997 & 0.997 \\
$S_{a}$ & 0.0325 & 0.0216 \\
$S_{b}$ & 0.0014 & 0.0005 \\
LOQ $(\mu \mathrm{g} / \mathrm{mL})$ & 0.6521 & 1.6884 \\
LOD $(\mu \mathrm{g} / \mathrm{mL})$ & 0.2152 & 0.5572 \\
\hline
\end{tabular}

${ }^{*} y=a+b x$, where $c$ is the concentration of RSP in $\mu \mathrm{g} / \mathrm{mL}, y$ is the absorbance at the respective $\lambda_{\max }, S_{a}$ is the standard deviation of the intercept, and $S_{b}$ is the standard deviation of the slope.

3.2.3. Effect of Time and Stability of the Complex. The optimum reaction time was evaluated by monitoring the color development upon the addition of reagent solution to RSP at room temperature. It was observed that the reaction got stabilized within 5 and 2 min in methods $\mathrm{A}$ and $\mathrm{B}$, respectively. The developed color was remained stable for $60 \mathrm{~min}$ at room temperature for both the methods.

3.3. Method Validation. According to the ICH guidelines [17], both the methods were validated for linearity and sensitivity, limit of detection (LOD) and limit of quantitation (LOQ), precision, accuracy, selectivity, and recovery.

3.3.1. Linearity, Sensitivity, Limits of Detection, and Quantification. To establish the linearity, accuracy, and precision under optimized experimental conditions for both methods $A$ and B. A linear correlation was found between the absorbance at respective wavelengths, and concentrations of RSP in the ranges are given in Table 1. Regression analysis of the calibration curve using the method of least squares was made to calculate the slope $(b)$, intercept $(a)$, and correlation coefficient $(r)$ for each method (methods A and B), and the values are presented in Table 1 . The optical characteristics such as absorption maxima, Beer's law limit, molar absorptivity, and Sandell's sensitivity values of two methods are also given in Table 1 .

The limit of detection (LOD) and limit of quantitation (LOQ) were evaluated as per ICH guidelines using the following equations:

$$
\begin{aligned}
& \mathrm{LOD}=\frac{3.3 \times \sigma}{s}, \\
& \mathrm{LOQ}=\frac{10 \times \sigma}{s},
\end{aligned}
$$

where $\sigma$ is the standard deviation $(n=5)$ of reagent blank determination, and $s$ is the slope of the calibration curve.

3.3.2. Precision and Accuracy. The precision and accuracy (intra-day and inter-day) of the methods developed were evaluated by replicate analysis of drug samples at three different concentrations (low, medium, and high) (Table 2) within the working limits, each being repeated five times. The RE (\%) and RSD (\%) values of both intra and inter-day studies were less than 2.0 and showed the best appraisal of the procedures in daily use:

$$
\mathrm{RE} \%=\left[\frac{\text { founded }- \text { added }}{\text { added }}\right] \times 100 .
$$

The analytical results obtained from this investigation are summarized in Table 2 . The values of percentage relative error between the concentrations of RSP for taken and found showed the high accuracy of the methods. The results obtained are presented in Table 2 and showed that the accuracy is good.

3.3.3. Application to Analysis of Pharmaceutical Samples. To check the validity of the proposed charge-transfer spectrophotometric methods, RSP was determined in some commercial formulations. The result obtained from the determination is in close agreement between the results obtained by the proposed methods and the label claim. Statistical analysis of the results using Student's $t$-test for accuracy and F-test for precision revealed no significant difference between the proposed methods and the literature method [12] at the 95\% confidence level with respect to accuracy and precision (Table $3)$. 
TABLE 2: Evaluation of accuracy and precision.

\begin{tabular}{|c|c|c|c|c|c|c|c|}
\hline \multirow{2}{*}{ Method } & \multirow{2}{*}{ RSP taken, $\mu \mathrm{g} / \mathrm{mL}$} & \multicolumn{3}{|c|}{ Intra-day accuracy and precision } & \multicolumn{3}{|c|}{ Inter-day accuracy and precision } \\
\hline & & RSP found ${ }^{*}, \mu \mathrm{g} / \mathrm{mL}$ & $\% \mathrm{RE}$ & $\%$ RSD & RSP found, $\mu \mathrm{g} / \mathrm{mL}$ & $\% \mathrm{RE}$ & $\%$ RSD \\
\hline \multirow{3}{*}{ Method A } & 5 & 4.98 & 0.43 & 0.41 & 5.03 & -0.49 & 0.23 \\
\hline & 15 & 14.89 & 0.74 & 0.39 & 15.05 & -0.33 & 0.24 \\
\hline & 20 & 19.93 & 0.35 & 0.28 & 20.14 & -0.67 & 0.39 \\
\hline \multirow{3}{*}{ Method B } & 5 & 4.98 & 0.42 & 0.79 & 5.11 & -2.28 & 0.79 \\
\hline & 20 & 19.78 & 0.94 & 0.35 & 20.03 & -0.12 & 0.39 \\
\hline & 40 & 39.89 & 0.28 & 0.27 & 40.12 & -0.29 & 0.53 \\
\hline
\end{tabular}

RE: relative error; RSD: relative standard deviation.

${ }^{*}$ Mean value of 5 determinations.

At the $95 \%$ confidence level for 4 degrees of freedom.

TABLE 3: Results of determination of RSP in tablets and statistical comparison with the reference method.

\begin{tabular}{lcccc}
\hline Tablet brand name & Nominal amount mg per tablet & Reference method [12] & Found ${ }^{* *}$ (\% of nominal amount \pm SD) \\
Method A & $100.18 \pm 0.14$ & $100.92 \pm 0.45$ \\
Respidon $^{\mathrm{a}}$ & $1 \mathrm{mg}$ & $102.0 \pm 0.18$ & $t=0.87, F=1.73$ & $t=2.68, F=6.23$ \\
\hline Rispond $^{\mathrm{b}}$ & & & $99.28 \pm 0.19 \quad$ & $101.16 \pm 0.45$ \\
& $1 \mathrm{mg}$ & $101.8 \pm 0.24$ & $t=1.04, F=0.66$ & $t=1.45, F=3.57$ \\
\hline
\end{tabular}

Marketed by: ${ }^{\mathrm{a}}$ (torrent (mind)), ${ }^{\mathrm{b}}$ (micro synapse); ${ }^{* *}$ mean value of five determinations.

Tabulated $t$ and $F$ values at $95 \%$ confidence level are 2.77 and 6.39 , respectively.

TABLE 4: Results of recovery experiments via the standard addition technique.

\begin{tabular}{|c|c|c|c|c|c|c|c|c|}
\hline \multirow[b]{2}{*}{ Tablet brand name } & \multicolumn{4}{|c|}{ Method A } & \multicolumn{4}{|c|}{ Method B } \\
\hline & $\begin{array}{l}\text { RSP tablet } \\
\mu \mathrm{g} / \mathrm{mL}\end{array}$ & $\begin{array}{c}\text { Pure RSP added, } \\
\mu \mathrm{g} / \mathrm{mL}\end{array}$ & $\begin{array}{l}\text { Total found } \\
\mu \mathrm{g} / \mathrm{mL}\end{array}$ & $\begin{array}{c}\text { Pure RSP } \\
\text { recovered }^{*} \\
\% \pm \mathrm{SD}\end{array}$ & $\begin{array}{l}\text { RSP tablet } \\
\mu \mathrm{g} / \mathrm{mL}\end{array}$ & $\begin{array}{c}\text { Pure RSP added, } \\
\qquad \mu \mathrm{g} / \mathrm{mL}\end{array}$ & $\begin{array}{l}\text { Total found } \\
\mu \mathrm{g} / \mathrm{mL}\end{array}$ & $\begin{array}{c}\text { Pure RSP } \\
\text { recovered }^{*} \\
\% \pm S D\end{array}$ \\
\hline \multirow{3}{*}{$\begin{array}{l}\text { Respidone } \\
\text { (torrent (mind)) }\end{array}$} & 5 & 5 & 9.97 & $99.22 \pm 0.19$ & 10 & 10 & 19.99 & $99.86 \pm 0.48$ \\
\hline & 5 & 10 & 15.10 & $100.91 \pm 0.11$ & 10 & 20 & 30.25 & $101.23 \pm 0.37$ \\
\hline & 5 & 15 & 20.08 & $100.42 \pm 0.13$ & 10 & 30 & 40.50 & $101.67 \pm 0.50$ \\
\hline \multirow{3}{*}{$\begin{array}{l}\text { Rispond } \\
\text { (micro synapse) }\end{array}$} & 5 & 5 & 9.92 & $98.38 \pm 0.16$ & 10 & 10 & 20.02 & $100.19 \pm 0.27$ \\
\hline & 5 & 10 & 15.02 & $100.16 \pm 0.23$ & 10 & 20 & 30.27 & $101.35 \pm 0.95$ \\
\hline & 5 & 15 & 19.89 & $99.28 \pm 0.19$ & 10 & 30 & 40.59 & $101.96 \pm 0.14$ \\
\hline
\end{tabular}

Mean value of three measurements.

3.3.4. Recovery Study by Standard Addition Technique. The accuracy and precision of the proposed methods for the determination of RSP in commercial sample were further ascertained by performing recovery studies. In this study, preanalyzed tablet powder was spiked with pure drug at three different concentrations, and the total was found by the proposed methods. Each determination was repeated three times. The recovery of the pure drug added was quantitative and revealed that coformulated substances did not interfere in the determination. The results of recovery study are compiled in Table 4.

\section{Conclusions}

The present paper describes two simple, accurate, precise, and sensitive extraction-free spectrophotometric methods for the determination of risperidone in bulk drug and in tablet.
The methods rely on the use of simple and cost-effective chemicals in both the methods and can be successfully applied to the routine estimation of risperidone in bulk and tablet dosage forms. From the calculated $t$ - and $F$ values at the $95 \%$ confidence level, it is clear that the results obtained by the proposed methods are in good agreement with those obtained by the reference method [12]. The small values of RE and RSD indicate the reliability, accuracy, and precision of suggested procedures. The results obtained in Tables 3 and 4 are considered to be of high accuracy, and, therefore, these methods can be recommended for the routine analysis of risperidone in quality control laboratories.

\section{Acknowledgments}

The authors are grateful to Cipla, India Ltd., for the generous supply of pure drug sample. H. N. Deepakumari is thankful 
to the University of Mysore, Mysore, India, for providing necessary facilities.

\section{References}

[1] European Pharmacopoeia, vol. 1, 5th edition, 2005.

[2] I. Grabnar, A. Mrhar, and I. Locatelli, "Simultaneous determination of risperidone and 9-hydroxyrisperidone enantiomers in human blood plasma by liquid chromatography with electrochemical detection," Journal of Pharmaceutical and Biomedical Analysis, vol. 50, no. 5, pp. 905-910, 2009.

[3] K. M. Kirschbaum, S. Finger, F. Vogel et al., "LC with columnswitching and spectrophotometric detection for determination of risperidone and 9-hydroxyrisperidone in human serum," Chromatographia, vol. 67, no. 3-4, pp. 321-324, 2008.

[4] A. Avenoso, G. Facciolà, M. Salemi, and E. Spina, "Determination of risperidone and its major metabolite 9-hydroxyrisperidone in human plasma by reversed-phase liquid chromatography with ultraviolet detection," Journal of Chromatography B, vol. 746, no. 2, pp. 173-181, 2000.

[5] X. Zhang, X. Zhao, C. Zhang et al., "Accuracy profile theory for the validation of an LC-MS-MS method for the determination of risperidone and 9-hydroxyrisperidone in human plasma," Chromatographia, vol. 71, no. 11-12, pp. 1015-1023, 2010.

[6] B. Čabovska, S. L. Cox, and A. A. Vinks, "Determination of risperidone and enantiomers of 9-hydroxyrisperidone in plasma by LC-MS/MS," Journal of Chromatography B, vol. 852, no. 1-2, pp. 497-504, 2007.

[7] C. Kousoulos, Y. Dotsikas, and Y. L. Loukas, "Turbulent flow and ternary column-switching on-line clean-up system for high-throughput quantification of risperidone and its main metabolite in plasma by LC-MS/MS. Application to a bioequivalence study," Talanta, vol. 72, no. 2, pp. 360-367, 2007.

[8] J. Bhatt, G. Subbaiah, and S. Singh, "Liquid chromatography/tandem mass spectrometry method for simultaneous determination of risperidone and its active metabolite 9hydroxyrisperidone in human plasma," Rapid Communications in Mass Spectrometry, vol. 20, no. 14, pp. 2109-2114, 2006.

[9] M. De Meulder, B. M. M. Remmerie, R. de Vries et al., "Validated LC-MS/MS methods for the determination of risperidone and the enantiomers of 9-hydroxyrisperidone in human plasma and urine," Journal of Chromatography B, vol. 870, no. 1, pp. $8-16,2008$

[10] O. V. Olesen and K. Linnet, "Simplified high-performance liquid chromatographic method for determination of risperidone and 9-hydroxyrisperidone in serum from patients comedicated with other psychotropic drugs," Journal of Chromatography $B$, vol. 698, no. 1-2, pp. 209-216, 1997.

[11] Z. A. El-Sherif, B. El-Zeany, and O. M. El-Houssini, "High performance liquid chromatographic and thin layer densitometric methods for the determination of risperidone in the presence of its degradation products in bulk powder and in tablets," Journal of Pharmaceutical and Biomedical Analysis, vol. 36, no. 5, pp. 975-981, 2005.

[12] M. S. Kumar, A. A. Smith, G. A. Vasagam, A. K. Muthu, and R. Manavalan, "Development of analytical method for risperidone by UV spectrophotometry," International Journal of Pharmaceutical Sciences and Research, vol. 1, pp. 122-126, 2010.

[13] W. E. S. Hassan, "Extractive colorimetric method for the determination of dothiepin hydrochloride and risperidone in pure and in dosage forms," Chemical and Pharmaceutical Bulletin, vol. 56, no. 8, pp. 1092-1096, 2008.
[14] J. Schuberth, "Volatile organic compounds determined in pharmaceutical products by full evaporation technique and capillary gas chromatography/ ion-trap detection," Analytical Chemistry, vol. 68, no. 8, pp. 1317-1320, 1996.

[15] W. C. Vosburgh and G. R. Cooper, "Complex ions. I. The identification of complex ions in solution by spectrophoto-metric measurements," Journal of the American Chemical Society, vol. 63, no. 2, pp. 437-442, 1941.

[16] M. E. Abdel-Hamid, M. A. Abdel-Salam, M. S. Mahrous, and M. M. Abdel-Khalek, "Utility of 7,7,8,8,tetracyanoquinodimethane and $p$-chloranilic acid in the qualitative and quantitative analysis of pentazocine," Journal de Pharmacie de Belgique, vol. 40, no. 4, pp. 237-243, 1985.

[17] International Conference On Harmonization of Technical Requirements for Registration of Pharmaceuticals for Human Use, ICH Harmonised Tripartite Guideline, Validation of Analytical Procedures: Text and Methodology Q2(R 1), Complementary Guideline on Methodology, dated 06 November 1996, incorporated in November 2005, London, UK. 

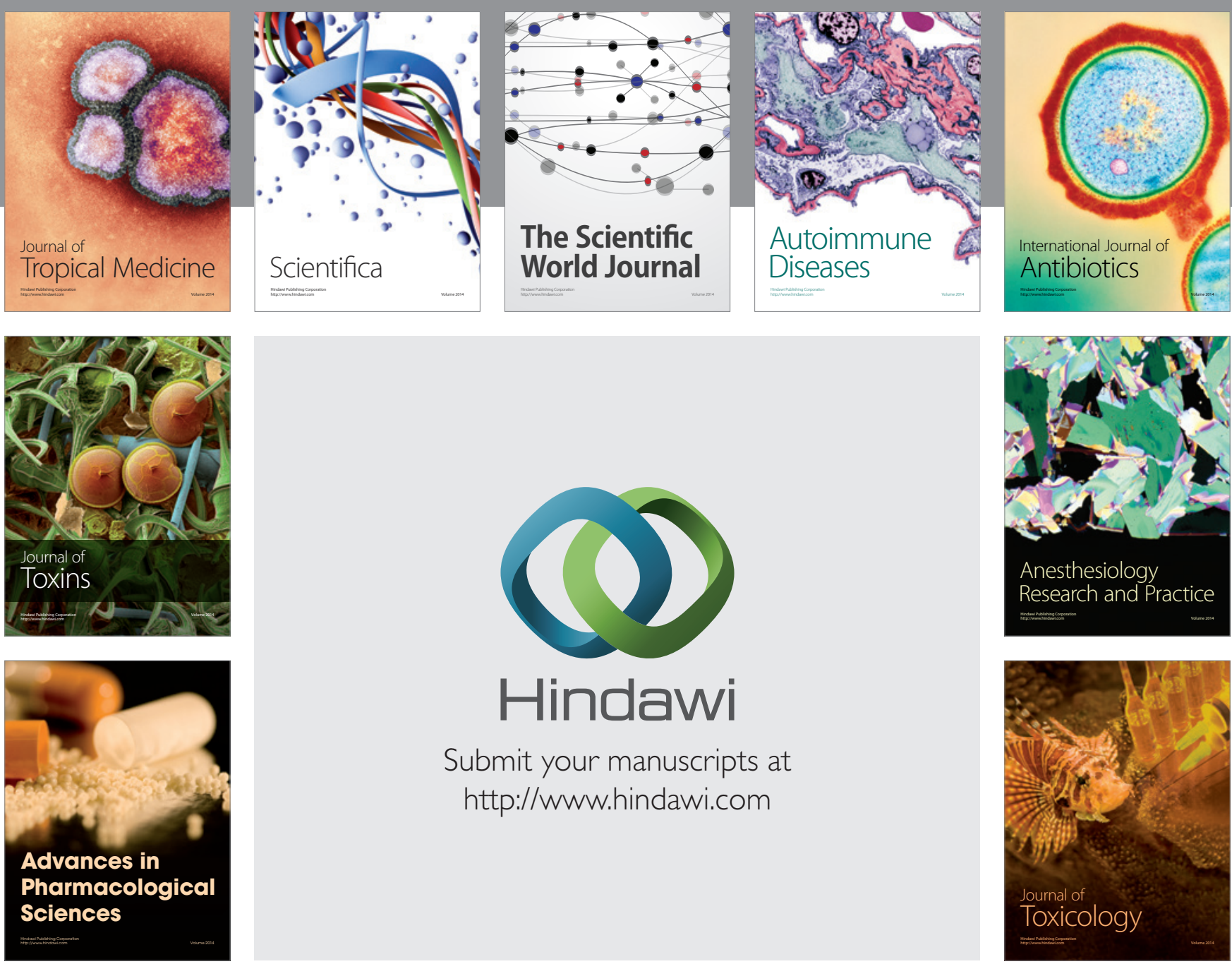

\section{Hindawi}

Submit your manuscripts at

http://www.hindawi.com
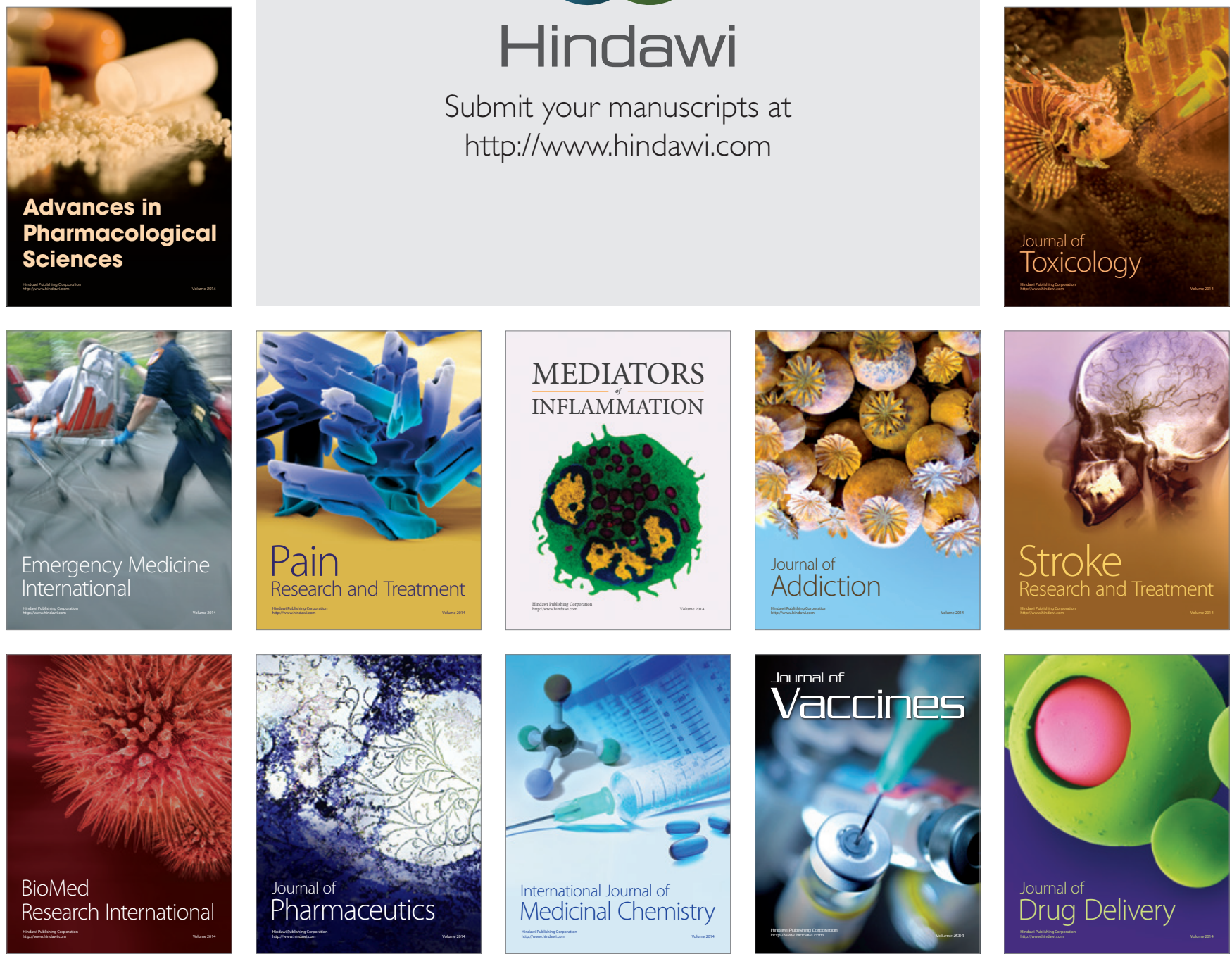